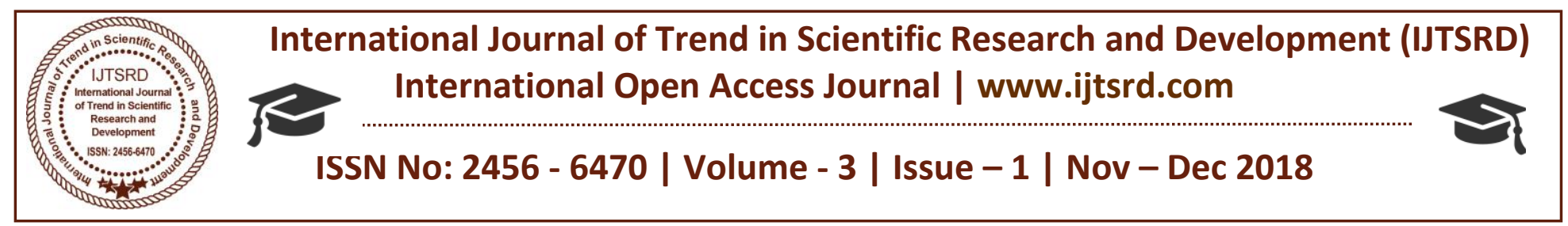

\title{
Evaluation of Ceiling Fan Blade Angle Performance using CFD
}

\author{
Yogesh Sanjay Bhawar, Dr. Arun N. Nanhai \\ Anuradha Engineering College, Chikhli, Maharashtra, India
}

\section{INTRODUCTION}

In the early days of aeronautics the flight of birds has stimulated scientists and engineers in the research and development of aircraft. Much has been learnt from nature and pioneers in the aeronautical field have studied the flight of birds. Birds move from one place to another by driving their wings in air. The motions of the bird in the air consist of flapping flight as well as gliding and soaring flight. Investigations on the aerodynamic characteristics of birds have been conducted for a variety of purposes. For example, an issue is formation flight of the birds as an energy saving mechanism during migration. Other investigations deal with aerodynamic characteristics of bird wings in steady flow conditions."In this simulation, the bird configuration is modelled at a fixed position and the flow does not change with time. However, there are also unsteady flight conditions, like yawing and rolling motions. Such movements produce a response of the airflow at the wing changing with time. This unsteady airflow affects the lateral-directional stability characteristics of birds.

\section{CAD, CFD THEORY AND WORKING \\ 3.1 COMPUTER AIDED DESIGN-}

- CREO Introduction

CAD technology is very important while designing any Product.

Following are advantages of CAD technology:

- To increase the productivity of the designer

Helping designer to conceptualize the product

Reducing time required to design and analyze.

- To improve the quality of the design

Allows the engineer to do a more complete engineering analysis and to consider a variety of design alternatives, therefore increasing quality.

\section{Normal fan blade@10 deg}

Fan blade wireframe model

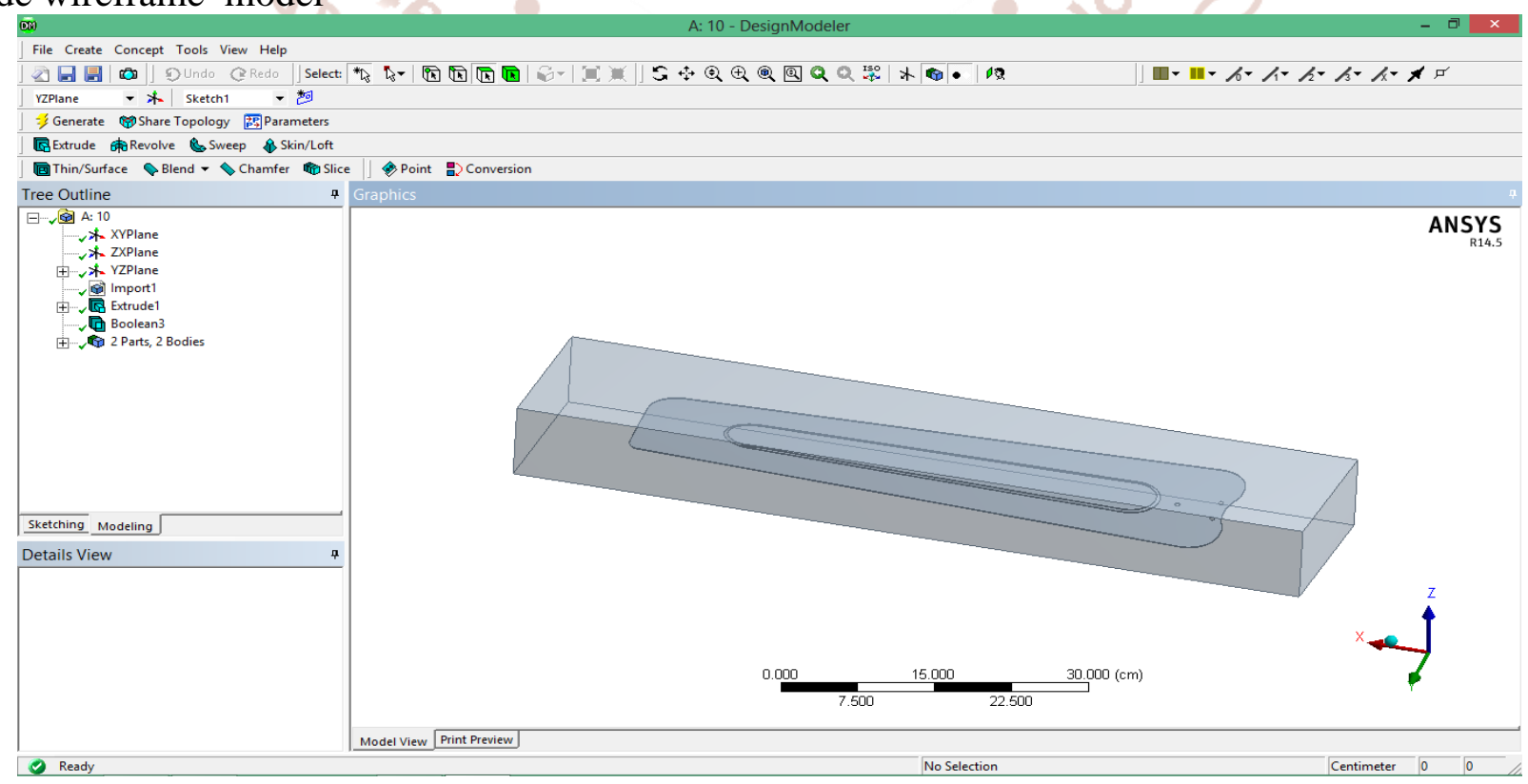

Fig 3.2: Fan blade wireframe model 
Fan blade wireframe model

\section{Normal fan blade @ 11 deg}

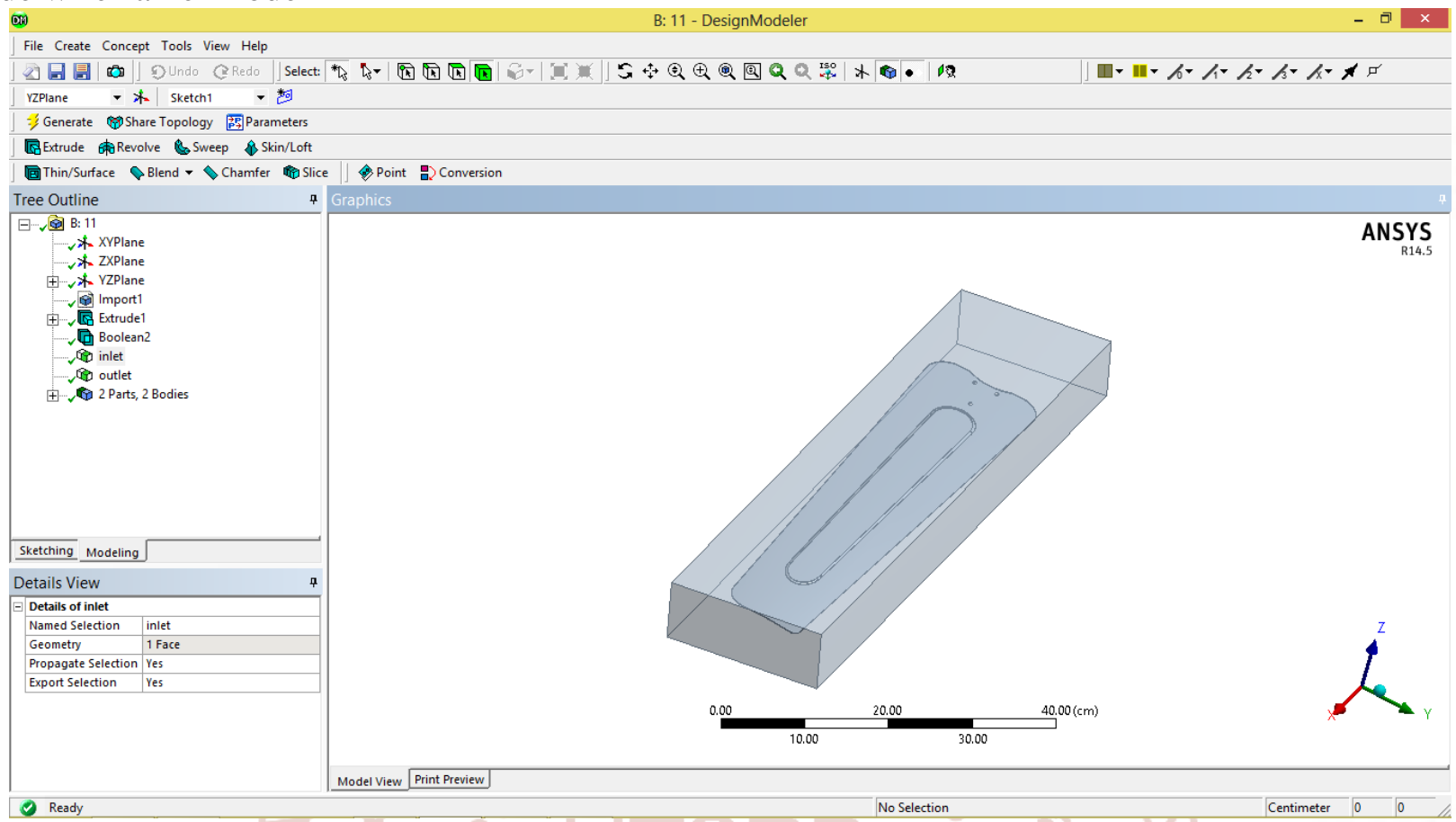

Fig 3.3: Fan blade wireframe model

Fan blade wireframe model

\section{Normal fan blade @ 12 deg}

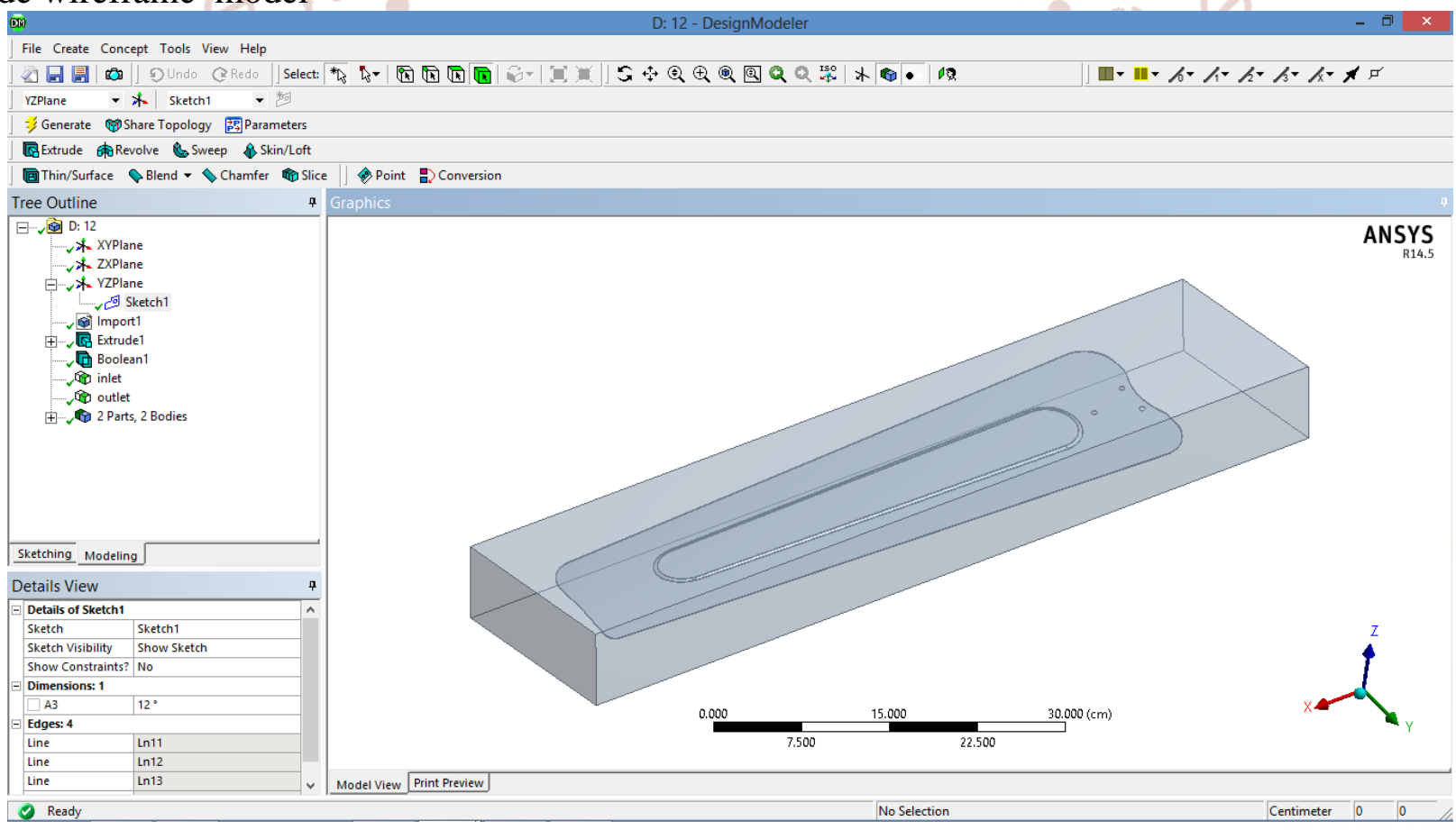

Fig 3.4: Fan blade wireframe model

\subsection{COMPUTATIONAL FLUID DYNAMICS-}

\subsubsection{INTRODUCTION}

The need to control and predict the movement of fluids is a common problem. The study of this area is called fluid dynamics and the systems that are studied range from global weather patterns, through aircraft aerodynamics to the way blood circulates. Computational Fluid Dynamics (CFD) takes these problems and solves them using a computer. 
International Journal of Trend in Scientific Research and Development (IJTSRD) ISSN: 2456-6470

CFD and its application is a rapidly developing discipline due to the continuous development in the capabilities of commercial software and the growth of computer power. CFD is already widely used in industry and its application is set to spread. This guide aims to provide an introduction to CFD and an overview of current software and techniques, including ways in which smart IT based methods can increase productivity.

Meshing

\section{Normal fan blade @ 10deg}

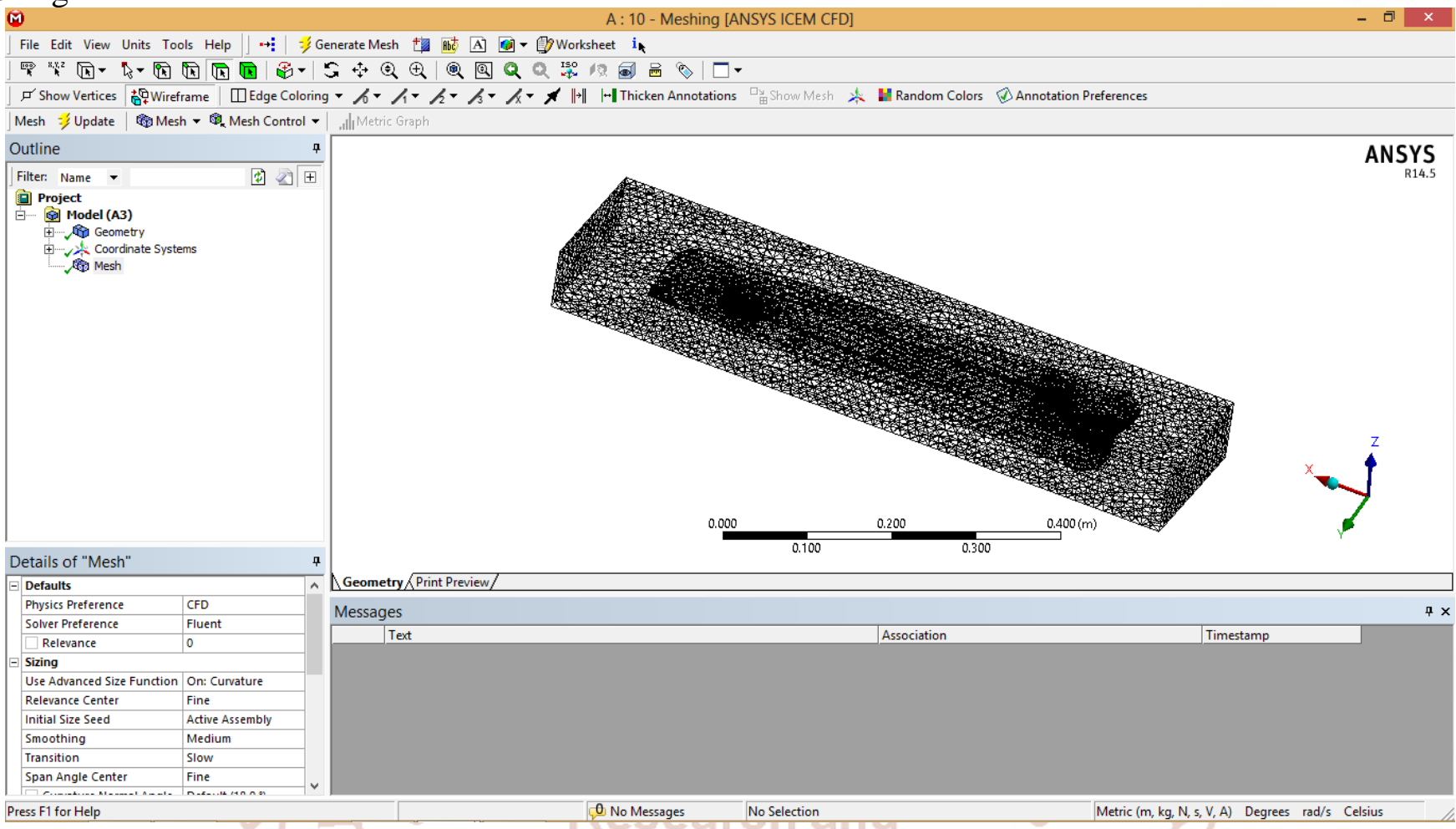

Fig 3.24: Meshing

Inlet

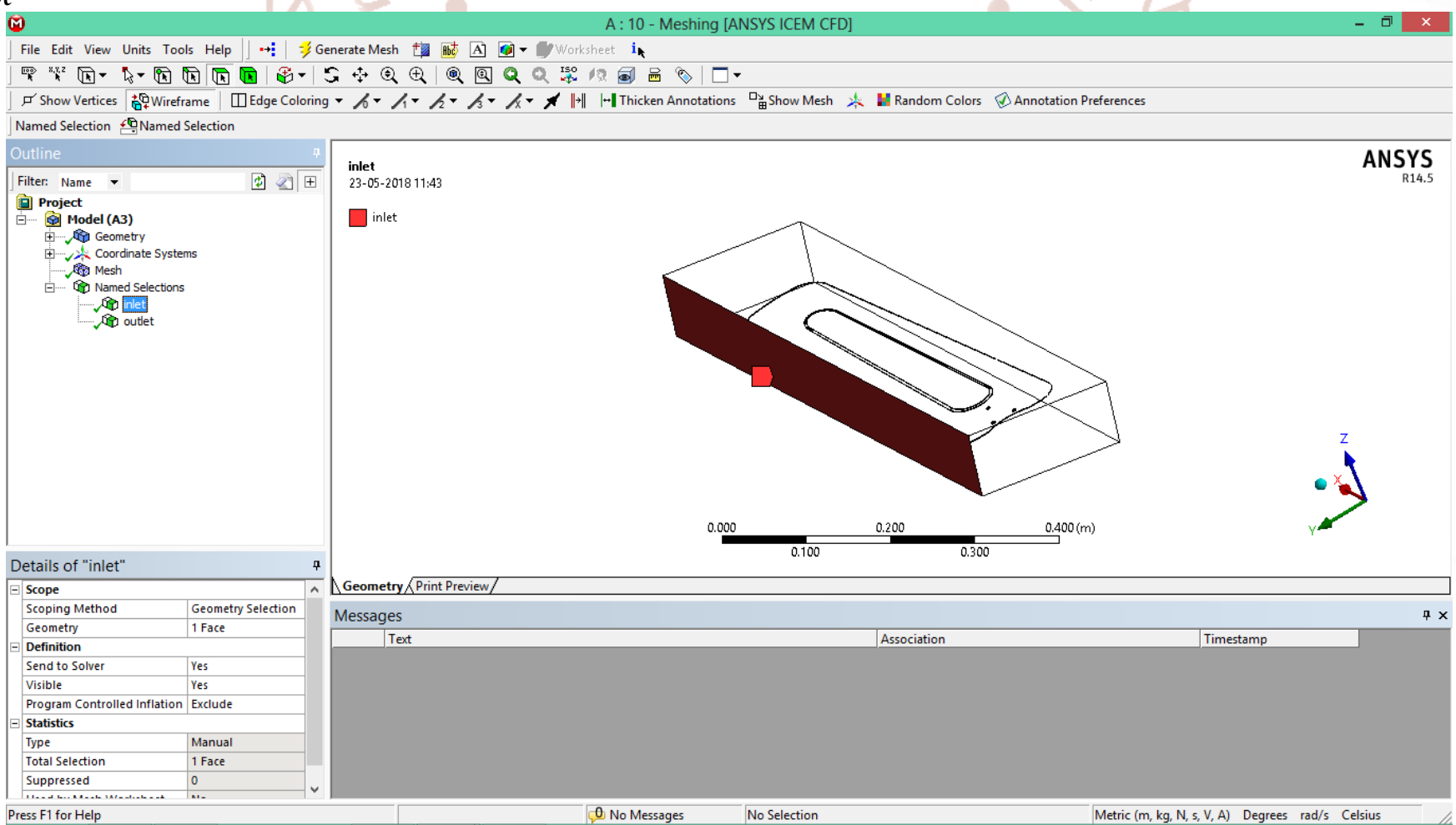

Fig 3.25: Inlet 
Outlet

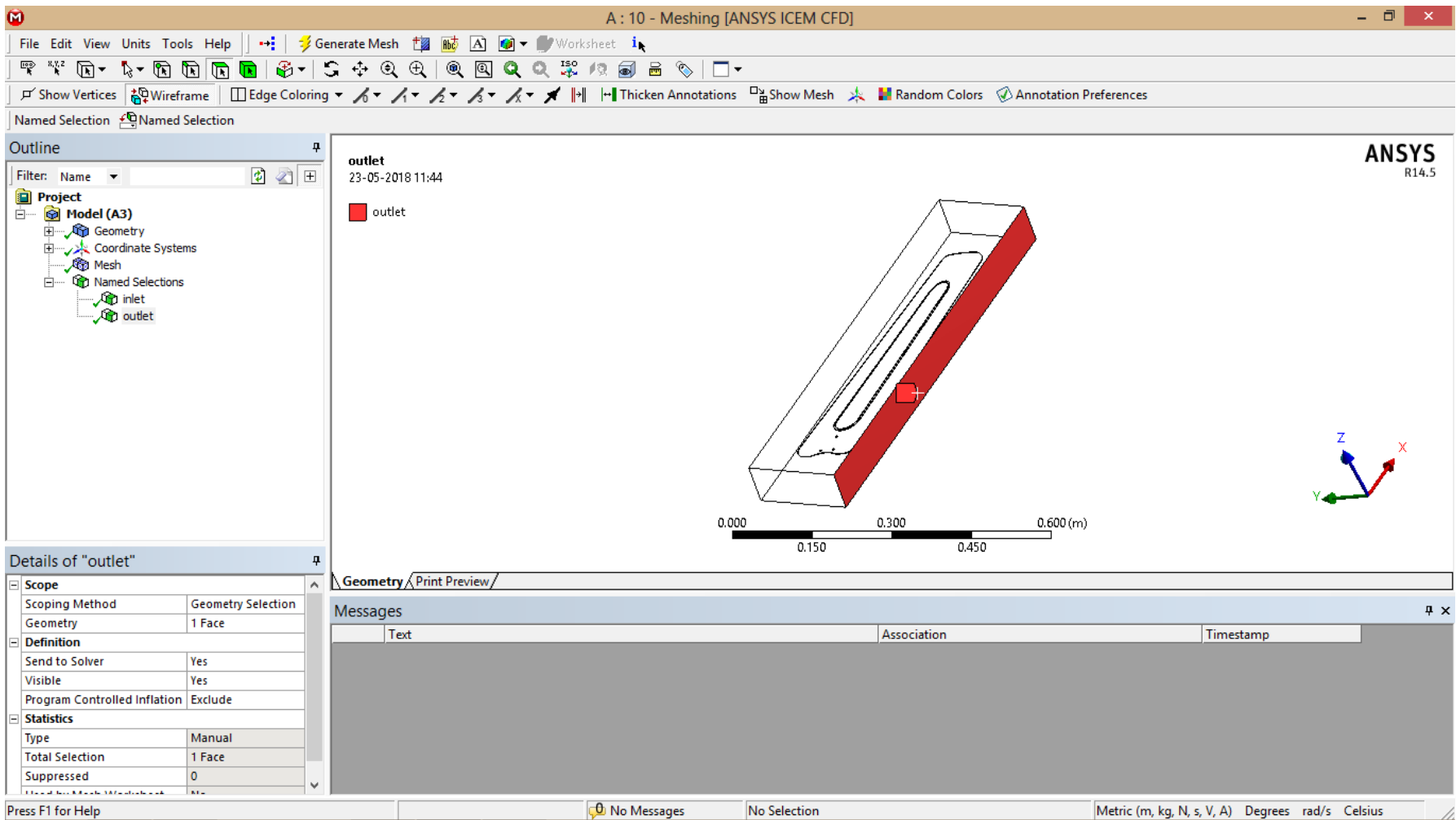

Fig 3.26: Outlet

Static Pressure counter

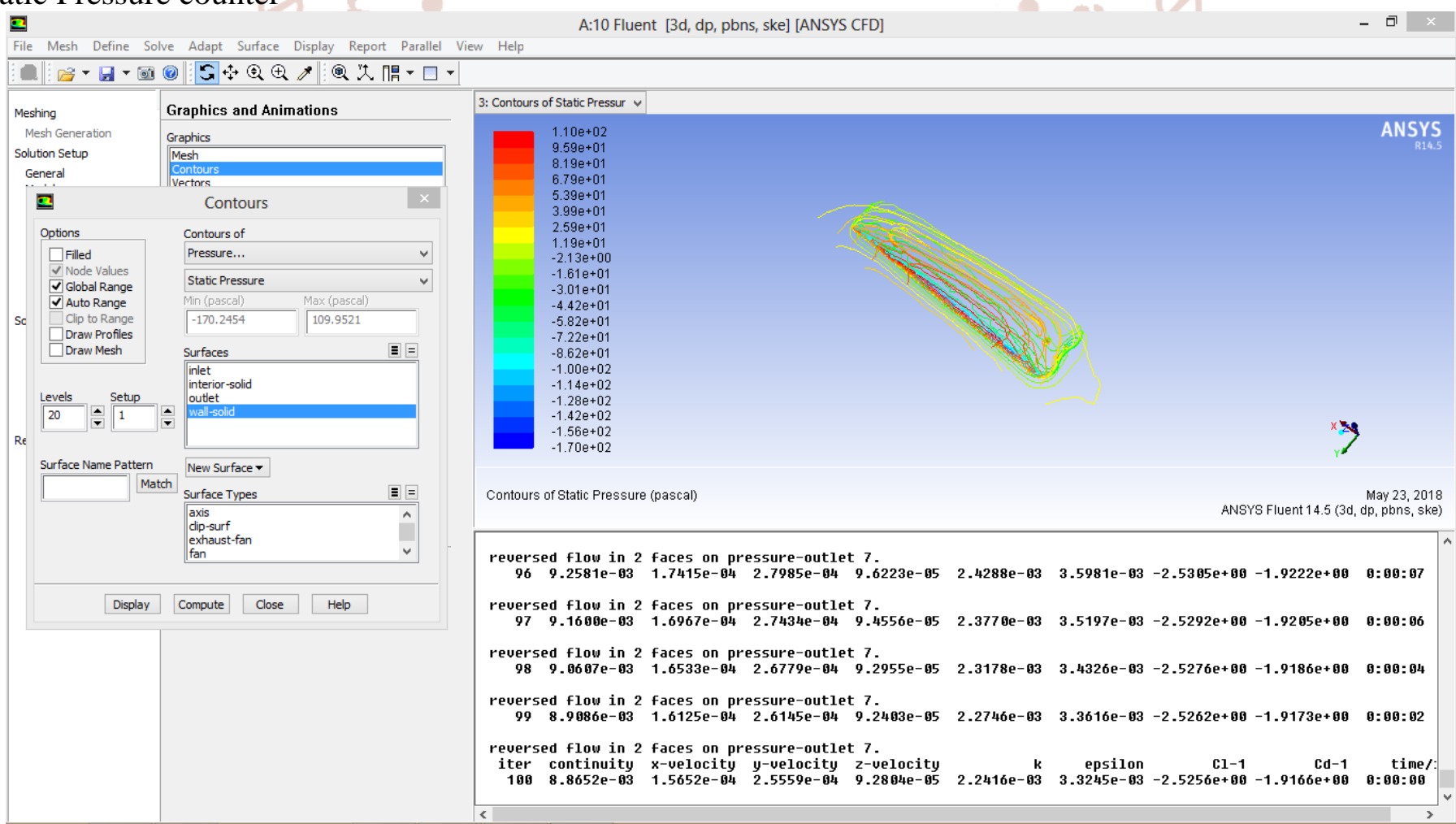

Fig 3.27: Static pressure counter 
International Journal of Trend in Scientific Research and Development (IJTSRD) ISSN: 2456-6470

Volume Rendering

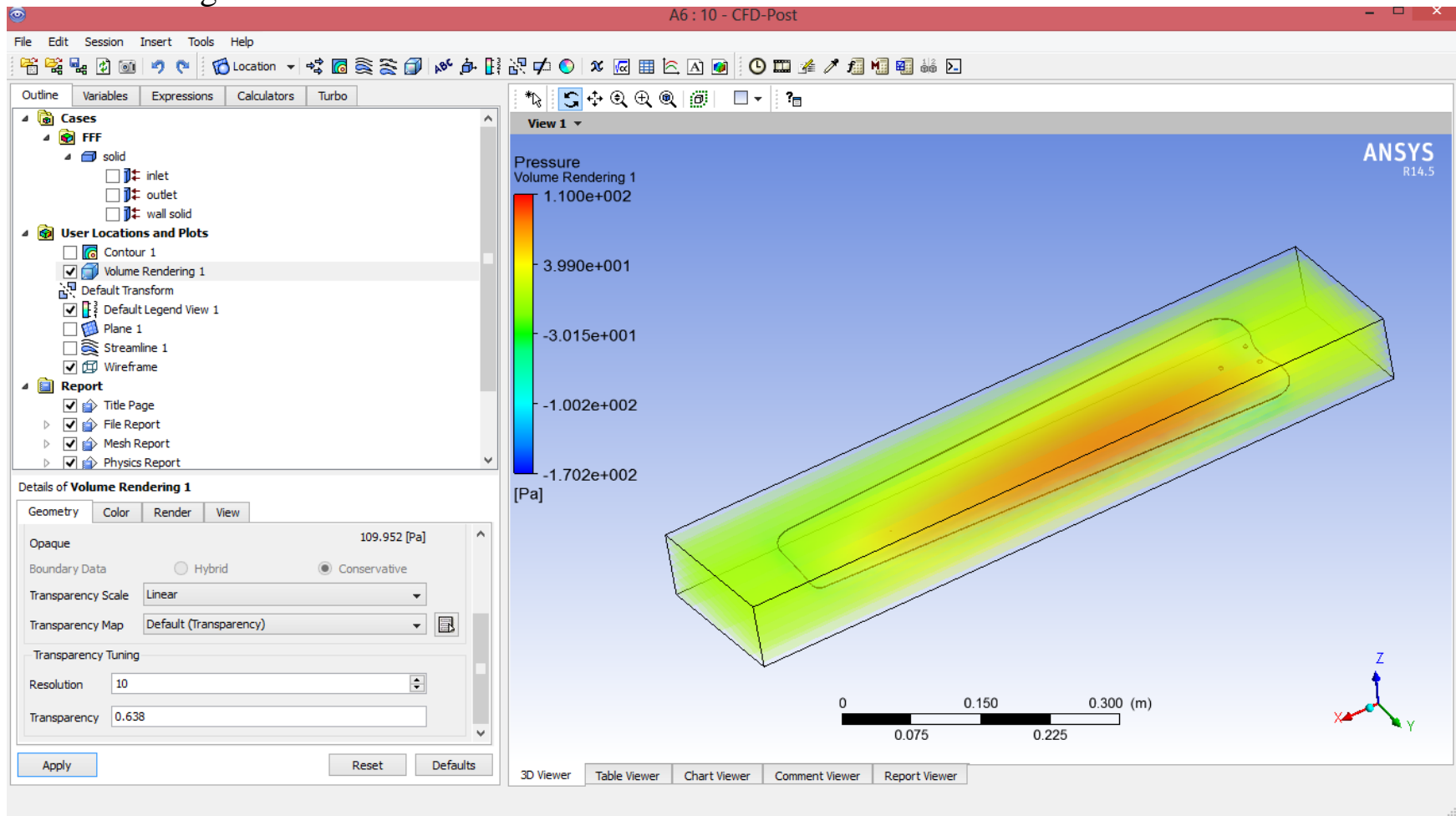

Fig 3.28: Volume rendering

Meshing

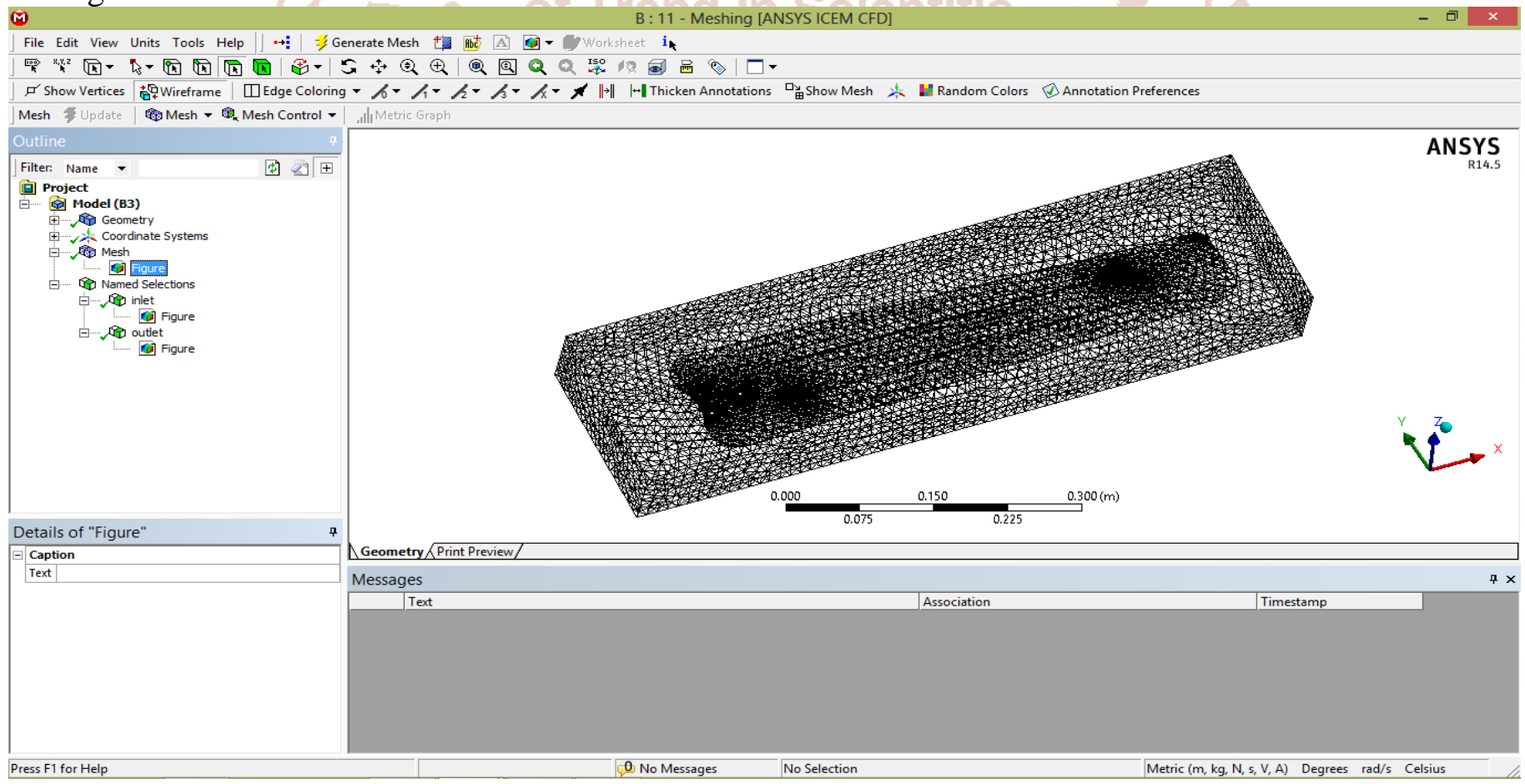

Normal fan blade @ 11deg

Fig 3.29: Meshing

Mesh Report

Table 3.1 Mesh Information for FFF 1

Domain Nodes Elements

Solid

$40281 \quad 213814$


Inlet

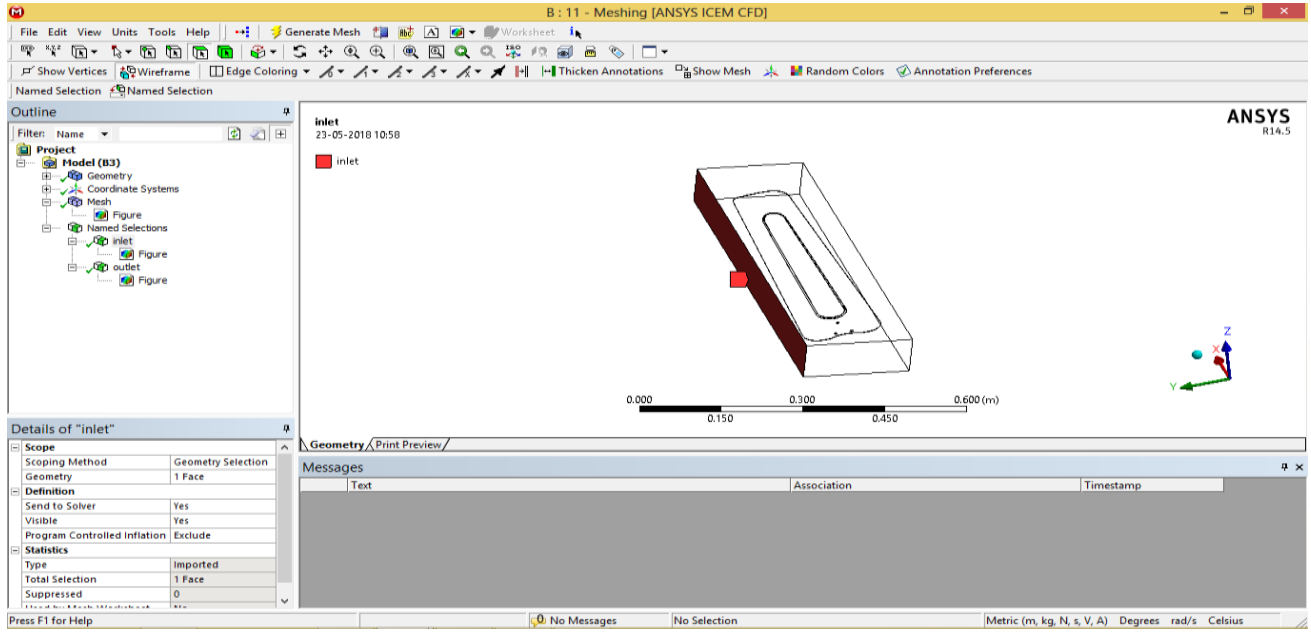

Fig 3.30: Inlet

Outlet

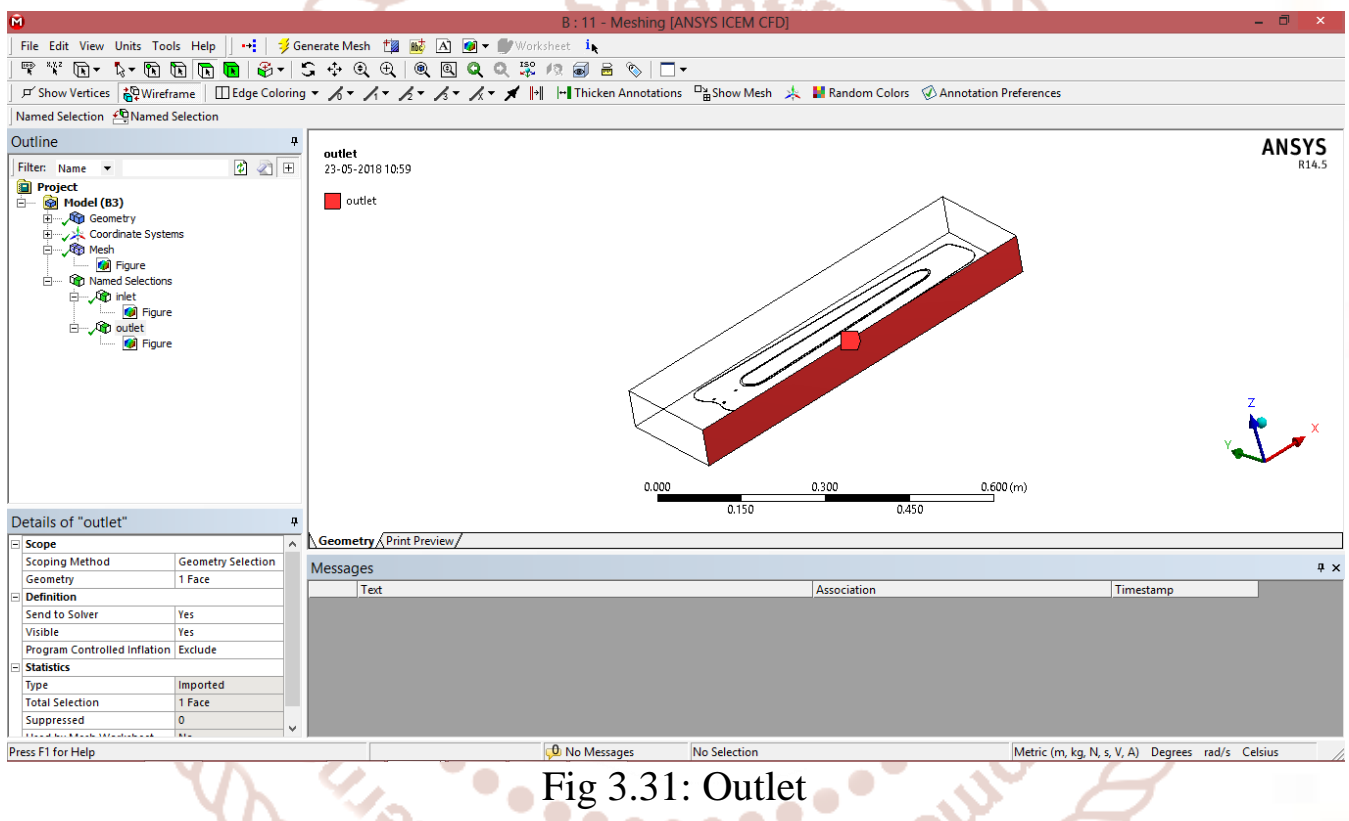

Static Pressure counter

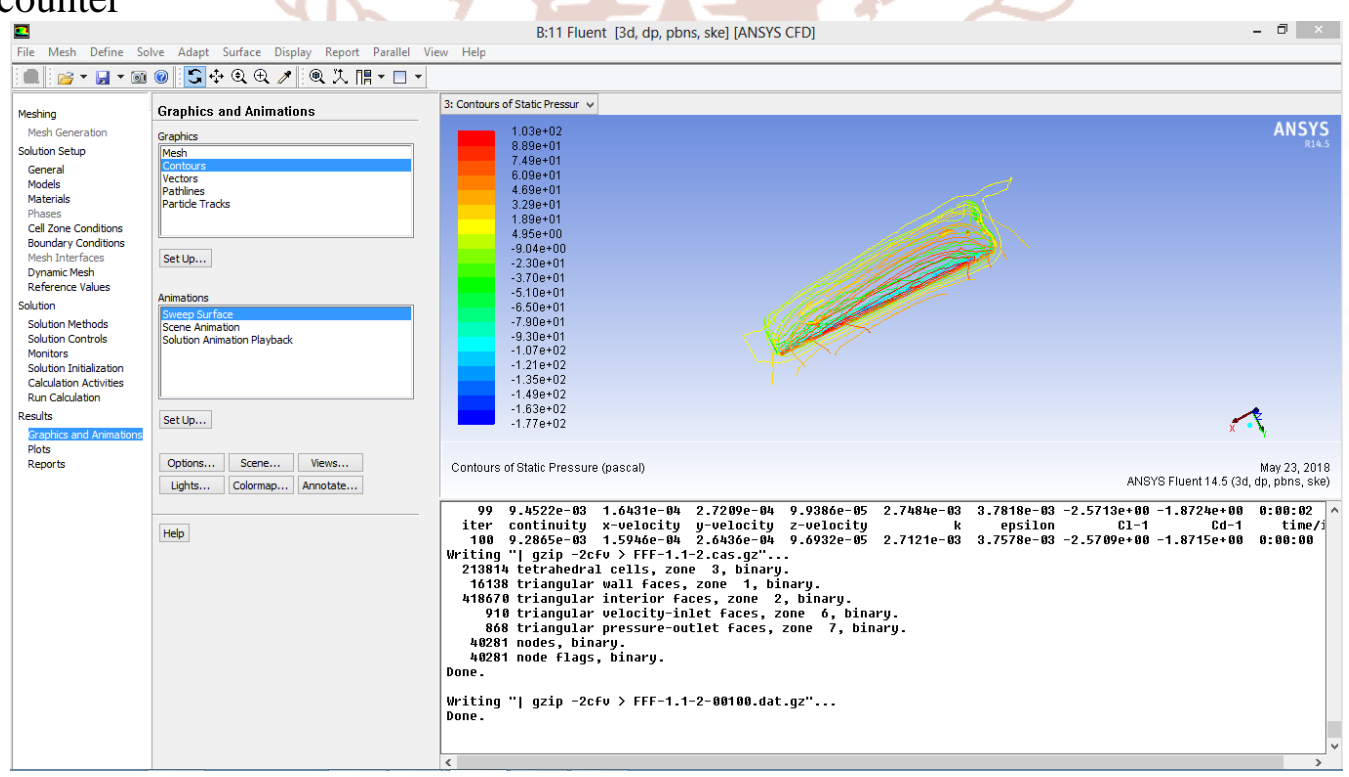

Fig 3.32: Static pressure counter 
International Journal of Trend in Scientific Research and Development (IJTSRD) ISSN: 2456-6470

Volume Rendering

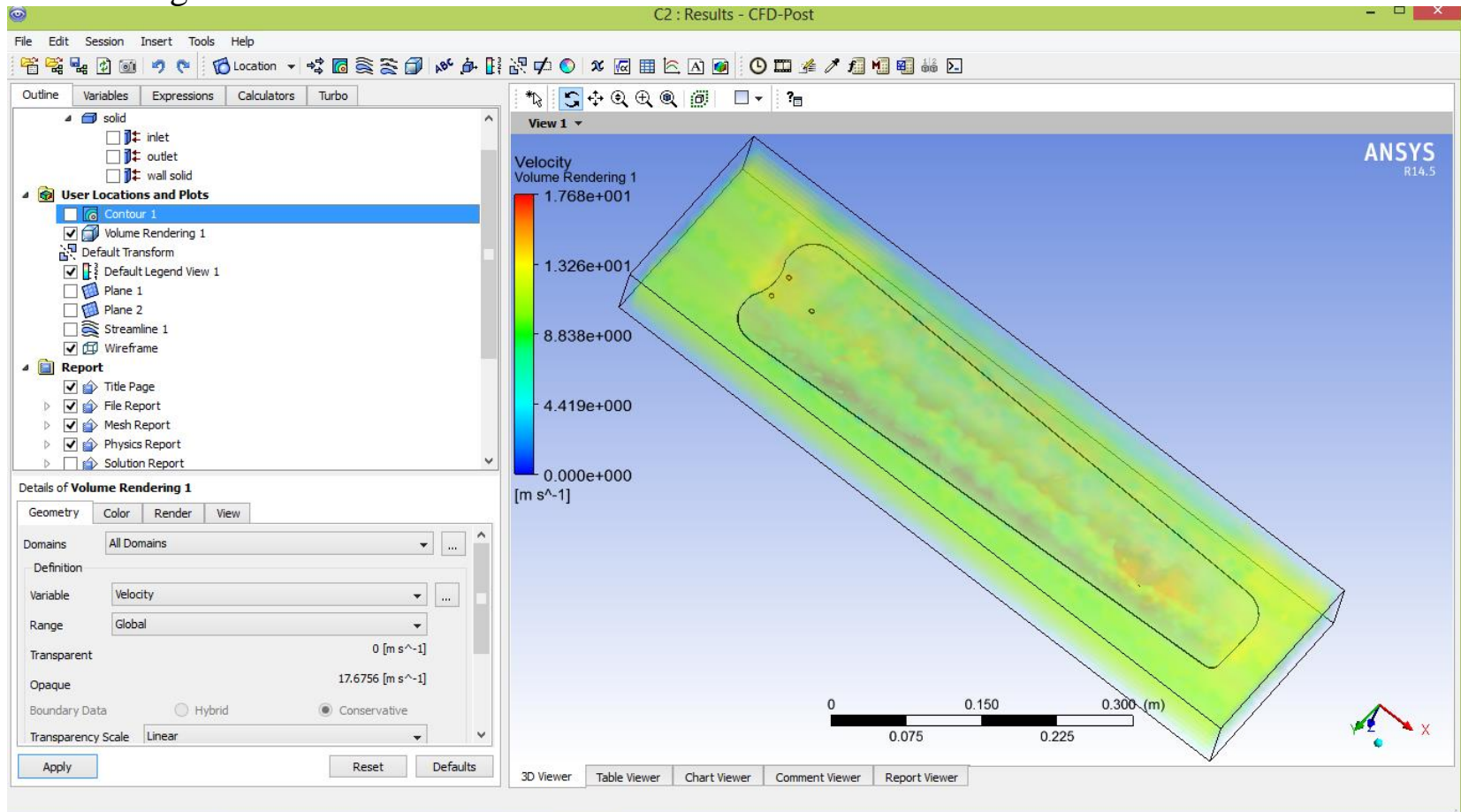

Fig 3.33: Volume rendering

\section{Normal fan blade @ 12 deg}

Meshing

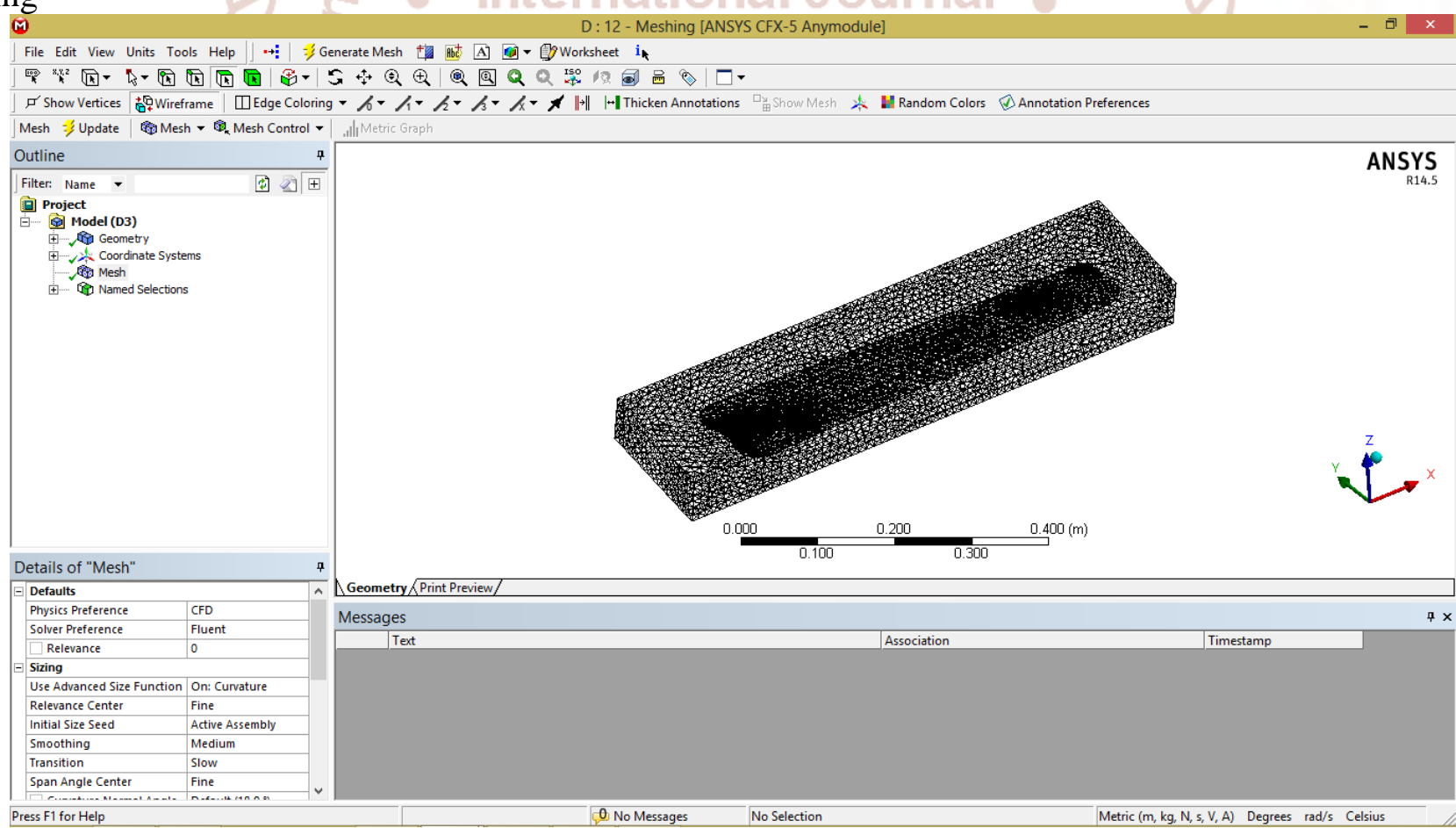

Fig 3.34: Meshing

\section{Mesh Report}

Table 3.2 Mesh Information for FFF 2

\begin{tabular}{|c|c|c|}
\hline Domain & Nodes & Elements \\
\hline Solid & 38052 & 201385 \\
\hline
\end{tabular}


Inlet

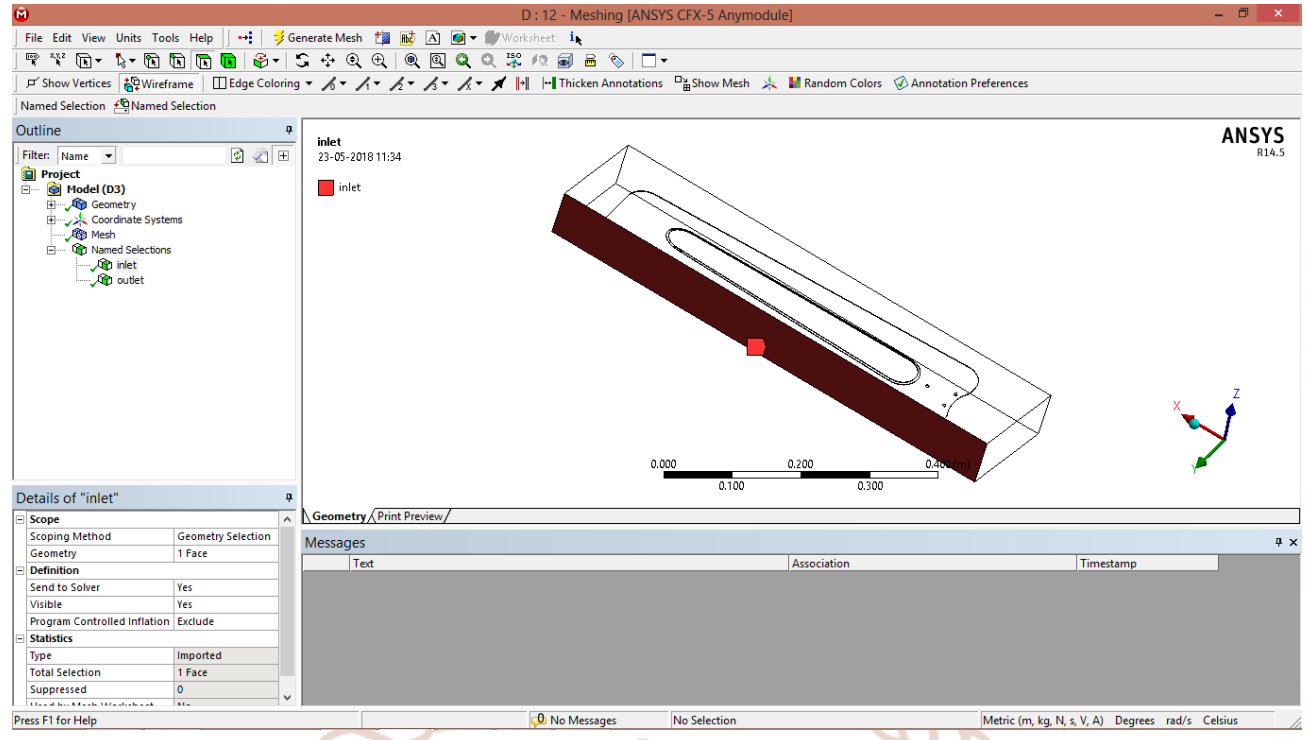

Fig 3.35: Inlet

Outlet

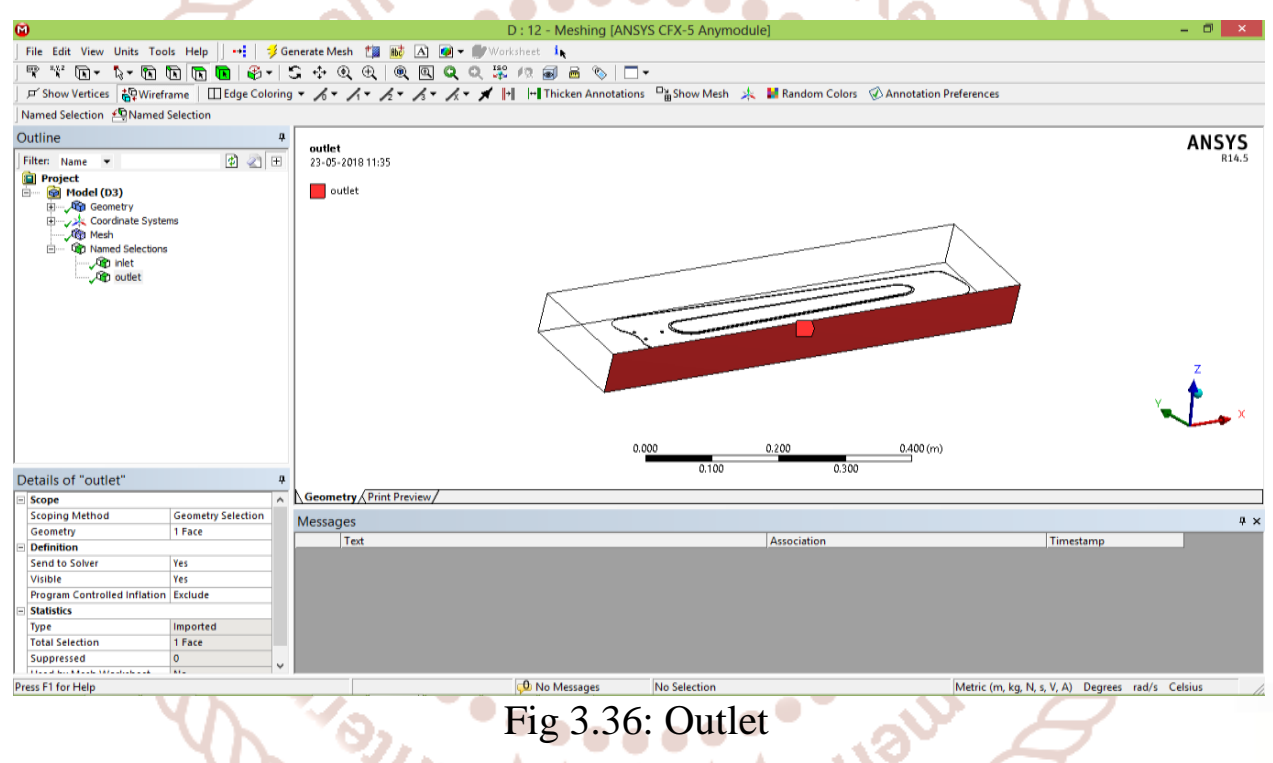

Static Pressure Counter

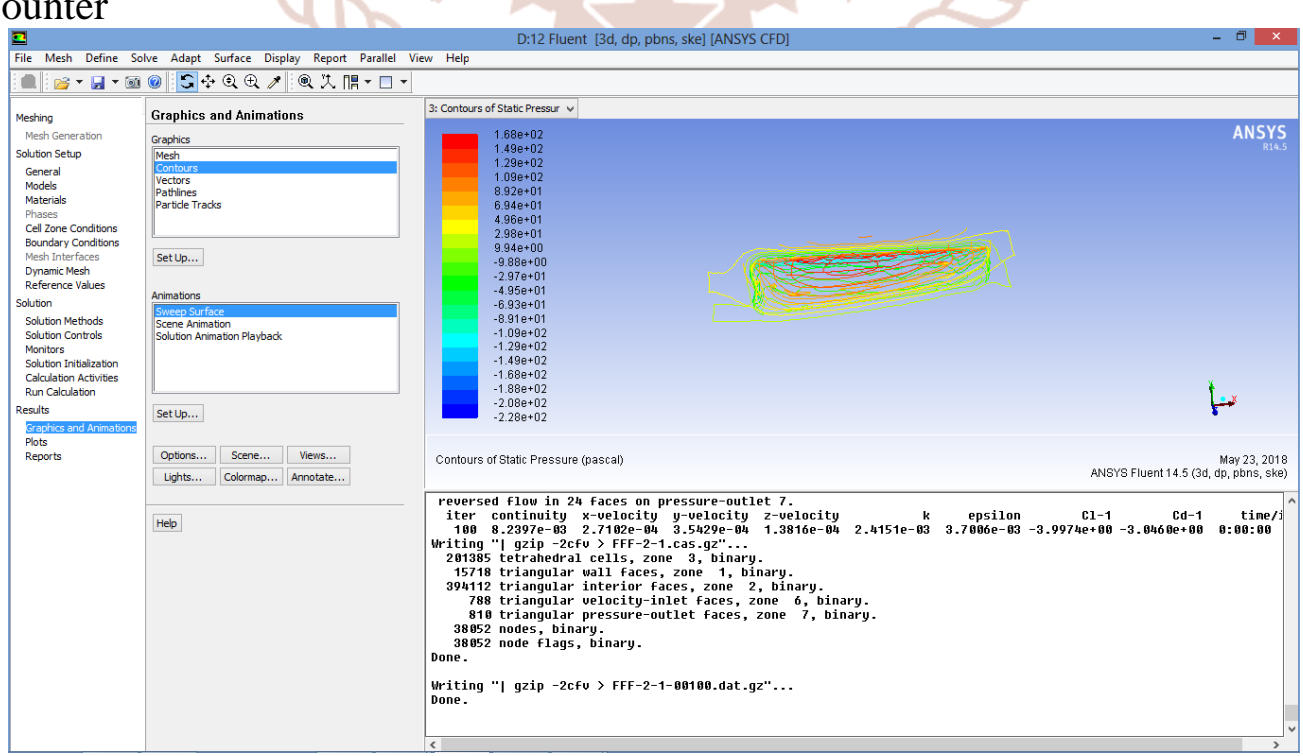

Fig 3.37: Static pressure counter 
International Journal of Trend in Scientific Research and Development (IJTSRD) ISSN: 2456-6470

Volume Rendering

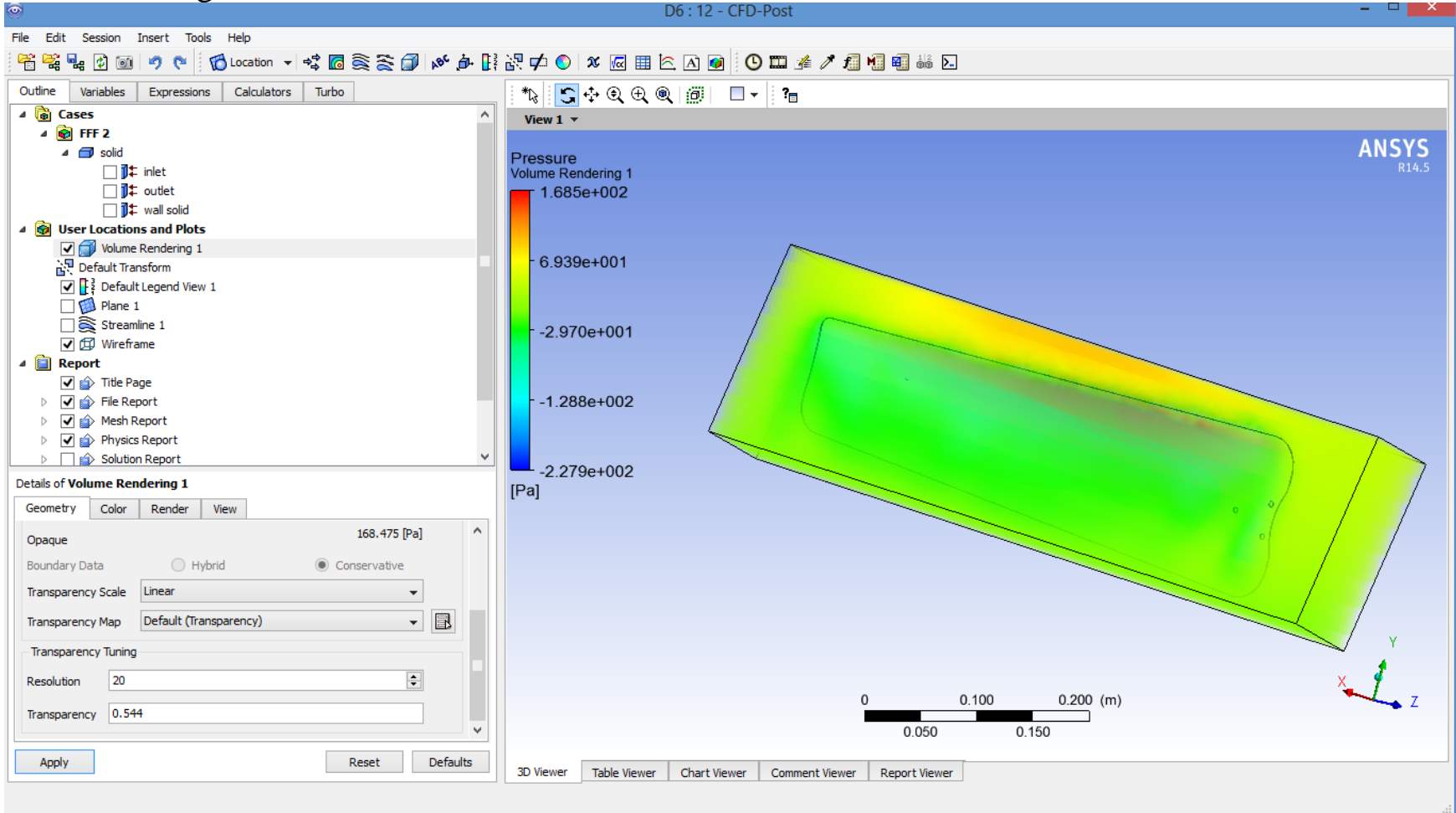

Fig 3.38: volume rendering

\section{Results}

The analysis was done for $\Theta=10^{0}, 11^{0}, 12^{\circ}$, where $\Theta$ is the angles of fan blade with horizontal;

Velocity Streamline

\section{RESULTS \\ Normal fan blade @ 10de}
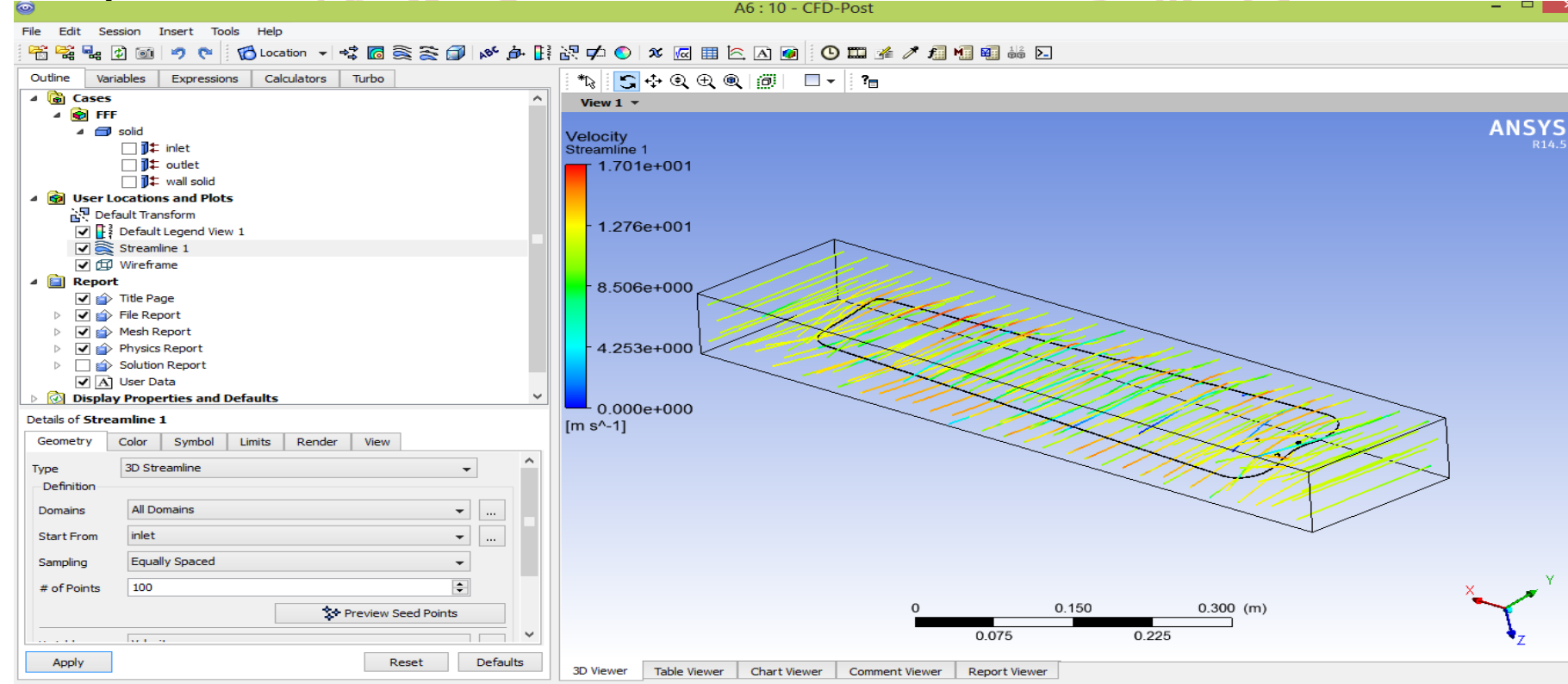

Fig 4.1: Velocity streamline 
International Journal of Trend in Scientific Research and Development (IJTSRD) ISSN: 2456-6470

Pressure counter

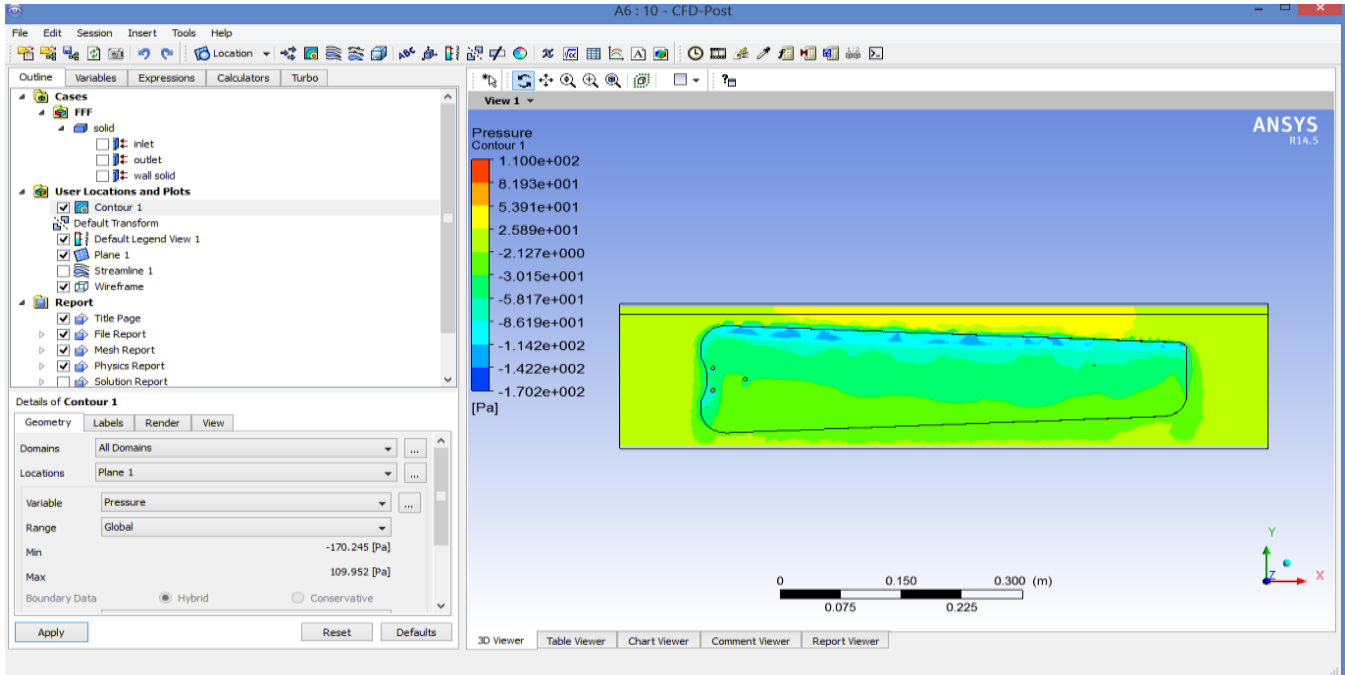

Fig 4.2: Pressure counter

\section{Normal fan blade @ 11deg}

Pressure Counter

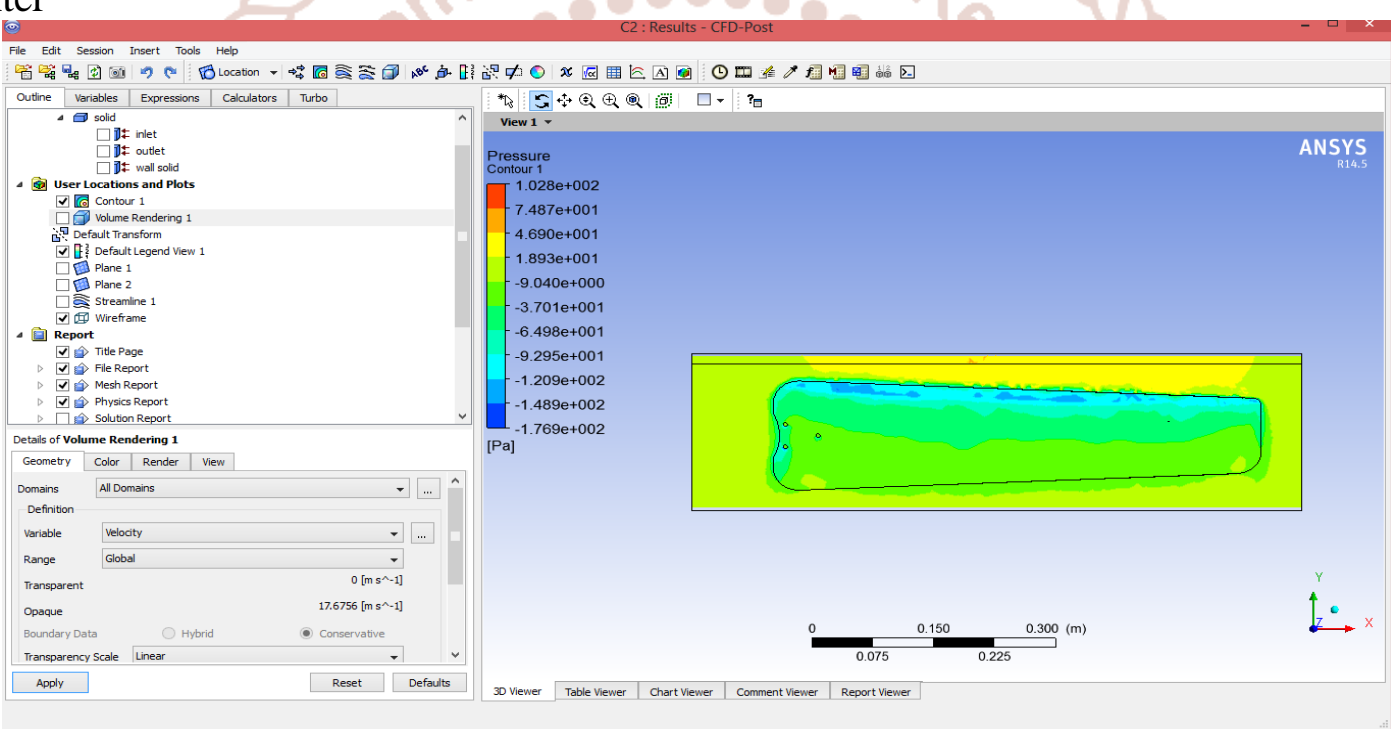

Velocity

Fig 4.3: Pressure counter

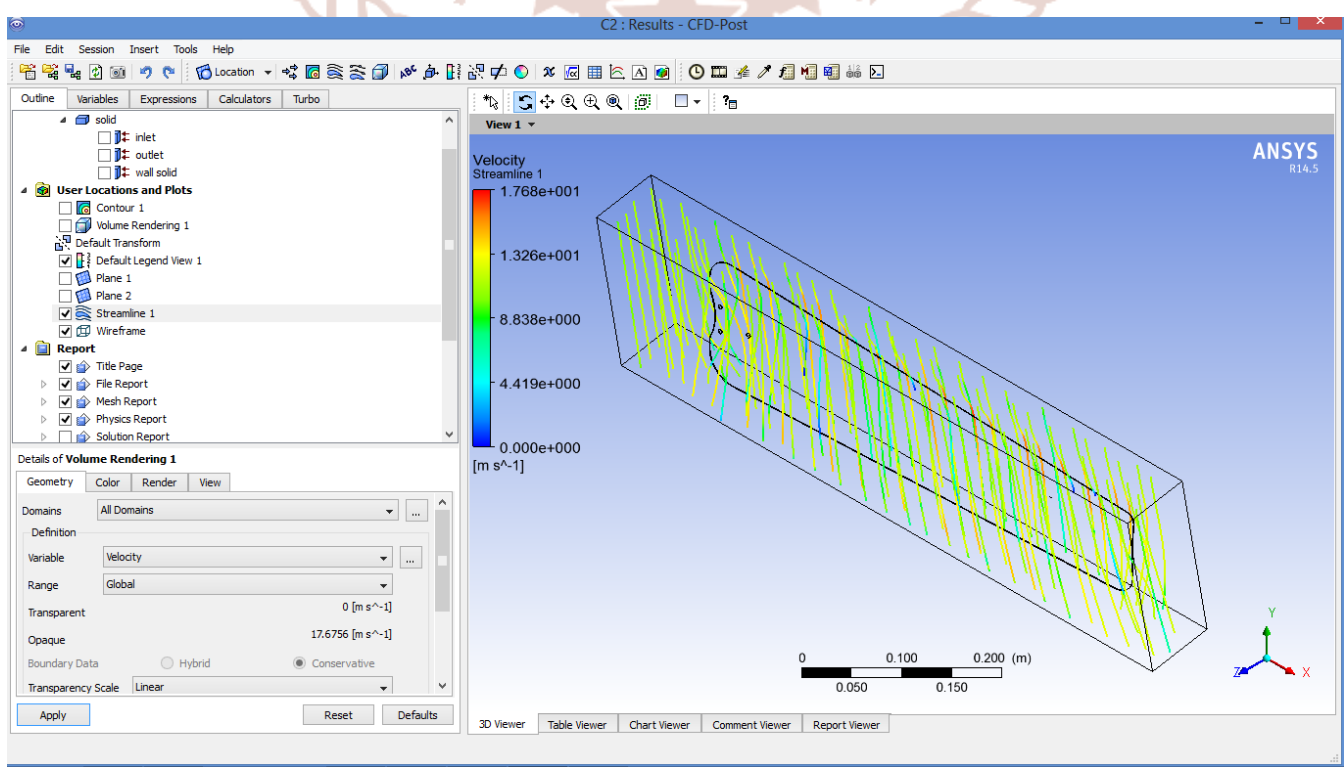

Fig 4.4: Velocity 
Velocity Streamline

\section{Normal fan blade @ 12 deg}

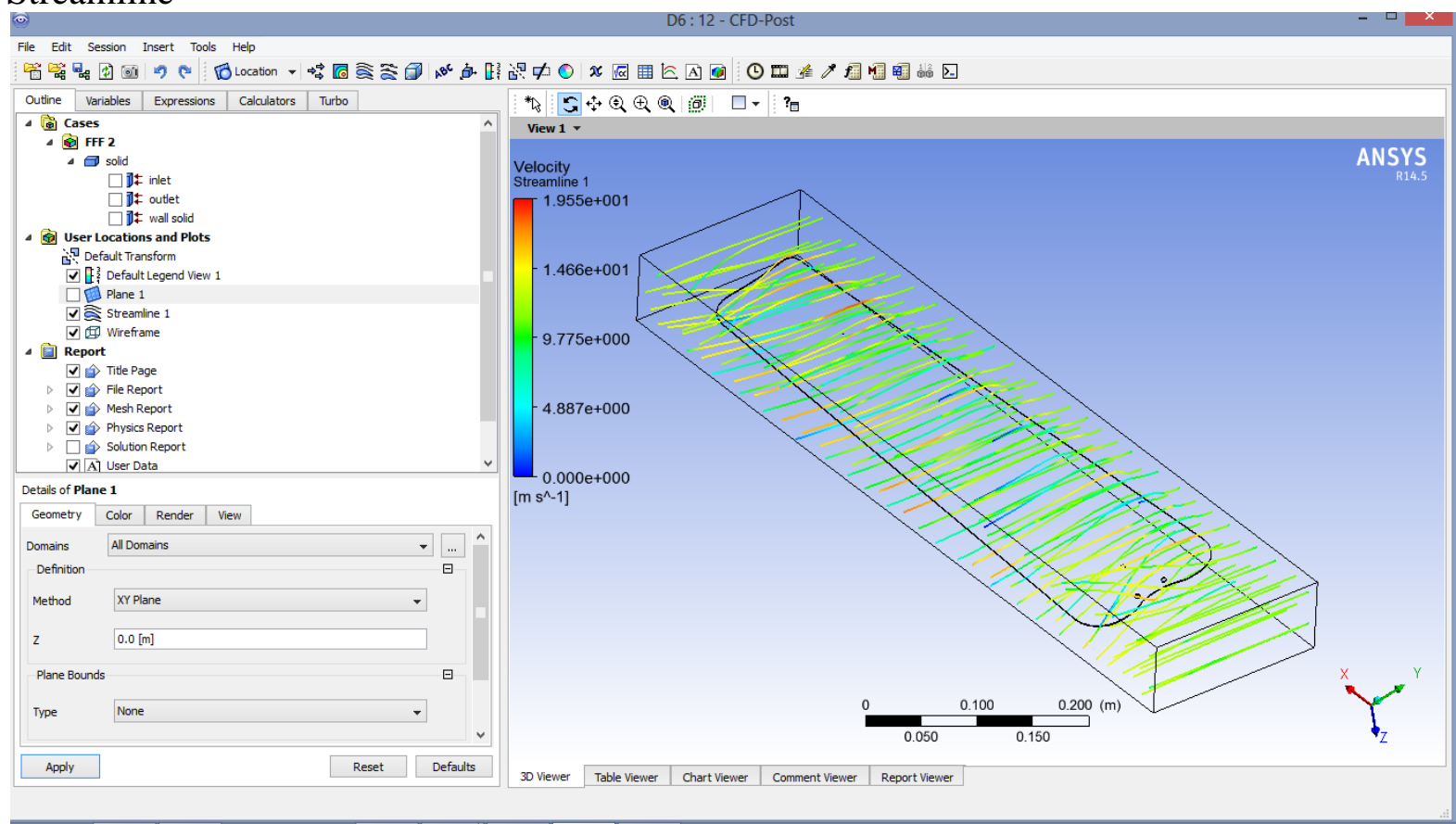

Pressure Counter

Fig 4.5: Velocity sreamline

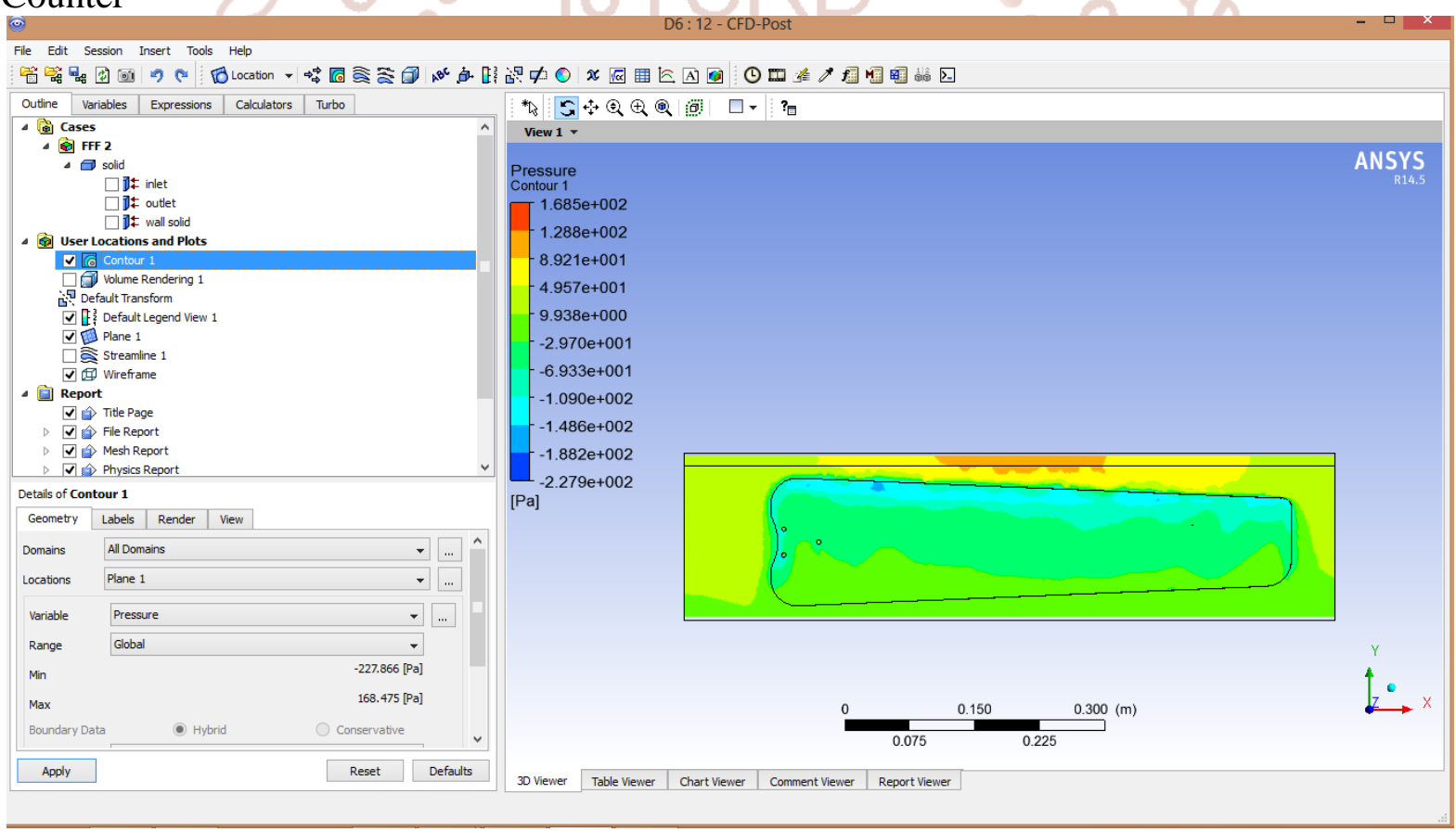

Fig 4.6: Pressure counter

Results

Table 4.1: Results for Normal fan blade

\begin{tabular}{|c|c|c|c|}
\hline Sr. No. & Blade angle & Velocity $(\mathrm{m} / \mathrm{s}) \max$ & Pressure(Pa) \\
\hline 1 & $10^{\circ}$ & 17.01 & 109.95 \\
\hline 2 & $11^{\circ}$ & 17.68 & 102.8 \\
\hline 3 & $12^{\circ}$ & 19.55 & 168.5 \\
\hline
\end{tabular}

Average Velocity for Normal Blade- $18.08 \mathrm{~m} / \mathrm{s}$

Average Pressure for Normal Blade- $127.08 \mathrm{~m} / \mathrm{s}^{2}$ 


\section{CONCLUSION}

From the above we have studied about Evaluation of Ceiling Fan Blade Angle Performance Using CFD by considering different fan blade design at different angle and we conclude from our analysis that normal blade with 12 deg has more speed at various angles we used.

We have taken different readings of Velocity and Pressure for different fan blade angles and we can say that normal blade with 12 deg has more average velocity and less average pressure.

This Analysis have been conducted to analyse the different blade angle by Computational Fluid Dynamics (CFD) in ANSYS software to finding the maximum air delivery. By finding maximum air delivery with their blade angle the optimum design is carried out by comparison of energy consumption i.e. power with different number of blades of ceiling fan. The experiments were conducted based on three different number of blades, have different blade angles, with constant speed and blade length and mathematical model was developed. Based on this analysis optimum design is achieved.

\section{REFERENCES}

1. Afaq, M. A., A. Maqsood, K. Parvez and A. Mushtaq(2014). Study on the design improvement of an indoor ceiling fan. 11th International Bhurban Conference on Applied Sciences and Technology, IEEE.
2. International Journal of Emerging Technology and Advanced Engineering 4(6), 247-251.

3. Fundamentals of Compressible Flow with Aircraft and Rocket propulsion by S.M. Yahaya

4. Auto Design by R.B. Gupta

5. ANSYS. (2013). ANSYS Fluent Theory Guide Canonsburg, PA.

6. ANSYS. (2016). ANSYS ${ }^{\circledR}$ Academic Research, Release 16.0, ANSYS Fluent in ANSYS Workbench User's Guide. ANSYS, Inc., Canonsburg, PA. Gambit. GAMBIT 5 User Guide, 1999.

7. Parker, D. S., M. P. Challahan, J. K. Sonne, G. H. Su and B. D. Hibbs (2000). Development of $a$ High Efficiency Ceiling Fan. Improving Building Systems in Hot and Humid Climates, Texas A\&M University.

8. Efficiency improvement opportunities for ceiling fans Nihar Shah \& Nakul Sathaye \& Amol Phadke \& Virginie Letschert

9. Technical Data Book, Prepared by Gulf Research and Development Company, Pittsburgh, PA, 1962.

10. REDESIGN OF CEILING FAN adapted to the Scandinavian market by Anna Eliasson \& Martina Westman • 070514 